\title{
An in situ x-ray photoelectron spectroscopy study of the initial stages of rf magnetron sputter deposition of indium tin oxide on p- type Si substrate
}

Cite as: Appl. Phys. Lett. 102, 021606 (2013); https://doi.org/10.1063/1.4774404

Submitted: 27 October 2012 • Accepted: 20 December 2012 • Published Online: 17 January 2013

M. H. Rein, M. V. Hohmann, A. Thøgersen, et al.

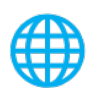

View Online

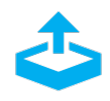

Export Citation

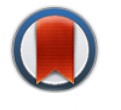

CrossMark

\section{ARTICLES YOU MAY BE INTERESTED IN}

Elemental distribution and oxygen deficiency of magnetron sputtered indium tin oxide films Journal of Applied Physics 109, 113532 (2011); https://doi.org/10.1063/1.3587174

Initial stages of ITO/Si interface formation: In situ x-ray photoelectron spectroscopy measurements upon magnetron sputtering and atomistic modelling using density functional theory

Journal of Applied Physics 115, 083705 (2014); https://doi.org/10.1063/1.4866991

Electrical, optical, and structural properties of indium-tin-oxide thin films for organic lightemitting devices

Journal of Applied Physics 86, 6451 (1999); https://doi.org/10.1063/1.371708

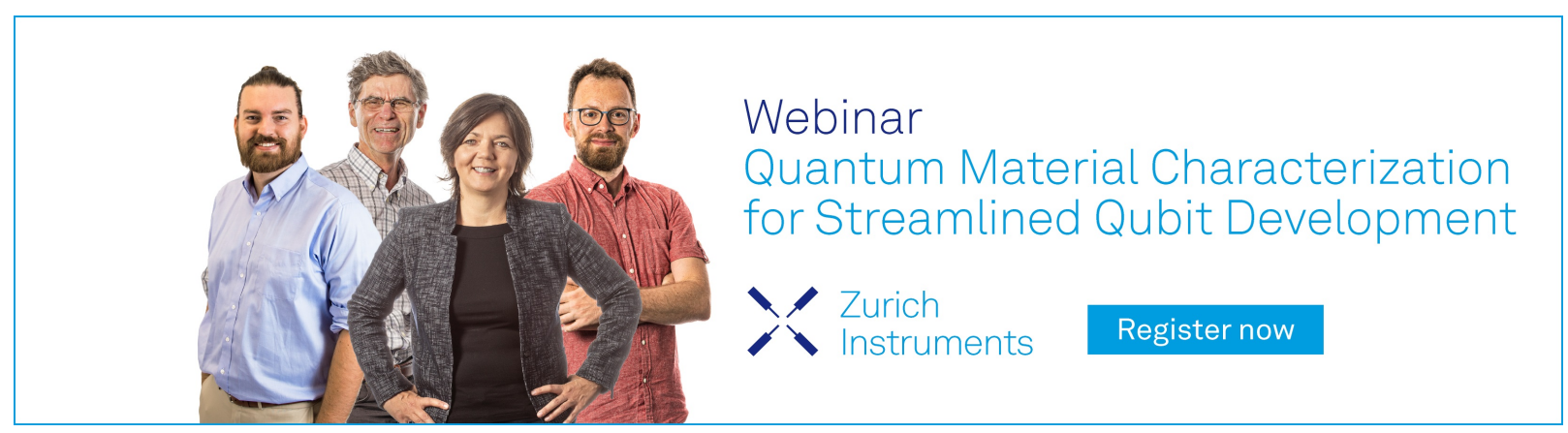




\title{
An in situ x-ray photoelectron spectroscopy study of the initial stages of rf magnetron sputter deposition of indium tin oxide on p-type Si substrate
}

\author{
M. H. Rein, ${ }^{1, a)}$ M. V. Hohmann, ${ }^{2}$ A. Thøgersen, ${ }^{3}$ J. Mayandi, ${ }^{4}$ A. O. Holt, ${ }^{1}$ A. Klein, ${ }^{2}$ \\ and E. V. Monakhov ${ }^{1,5}$ \\ ${ }^{1}$ Institute for Energy Technology, Department of Solar Energy, Instituttveien 18, 2008 Kjeller, Norway \\ ${ }^{2}$ Technische Universität Darmstadt, Institute of Materials Science, Surface Science Division, \\ Petersenstrasse 32, D-64287 Darmstadt, Germany \\ ${ }^{3}$ SINTEF-Materials and Chemistry Syntesis and Properties, Forskningsveien 1, Pb. 124 Blindern, 0314 Oslo, \\ Norway \\ ${ }^{4}$ Department of Materials Science, School of Chemistry, Madurai Kamaraj University, Tamil Nadu, Madurai, \\ India \\ ${ }^{5}$ Department of Physics/Centre for Materials Science and Nanotechnology, University of Oslo, 0316 Oslo, \\ Norway
}

(Received 27 October 2012; accepted 20 December 2012; published online 17 January 2013)

\begin{abstract}
The interface between indium tin oxide and p-type silicon is studied by in situ X-ray photoelectron spectroscopy (XPS). This is done by performing XPS without breaking vacuum after deposition of ultrathin layers in sequences. Elemental tin and indium are shown to be present at the interface, both after 2 and $10 \mathrm{~s}$ of deposition. In addition, the silicon oxide layer at the interface is shown to be composed of mainly silicon suboxides rather than silicon dioxide. (C) 2013 American Institute of Physics. [http://dx.doi.org/10.1063/1.4774404]
\end{abstract}

Despite the growing number of available transparent conducting materials (TCMs), indium tin oxide (ITO) is still the most preferable TCM for a number of applications due to its excellent electrical and optical properties. ${ }^{1}$ When ITO is deposited on a $\mathrm{Si}$ substrate a thin $(1-3 \mathrm{~nm})$ silicon oxide $\left(\mathrm{SiO}_{\mathrm{x}}\right)$ layer is established, due to the thermodynamics of this formation. ${ }^{2}$ The properties of this interfacial layer may influence the operation of a device, such as solar cells. ${ }^{3}$ For instance, Goodnick et al. showed a thermal degradation of ITO/p-Si solar cells due to growth of additional interfacial $\mathrm{SiO}_{\mathrm{x}} \cdot{ }^{4}$

X-ray photoelectron spectroscopy (XPS) is a suitable characterization method for the study of physical and chemical properties of the $\mathrm{SiO}_{x}$ layer and the ITO/Si interface. Chemical analysis of bonds between elements in an ITO/Si interface is previously carried out by the use of ex situ XPS of ultrathin ITO films on monocrystalline Si and XPS depth profiling of ITO on monocrystalline silicon and amorphous silicon. ${ }^{-7}$

XPS is a characterization method which is sensitive to surface contamination. For instance, carbon impurities are previously proven to affect the work function value of ITO measured by XPS. ${ }^{8}$ Thus, in order to avoid influence by any contamination, a cleaning procedure prior the spectroscopy is required. Cleaning the sample by ion bombardment will remove most of the impurity elements, though, some atoms will still remain at the surface. A drawback of ion bombardment is that it may induce side-effects such as chemical changes in the material, as described in Ref. 9, and references therein. One type of chemical change can be depletion of certain elements when the material is a compound. This can either be due to different sputtering yield or due to preferential sputtering caused by higher volatility of one element. In

\footnotetext{
${ }^{\text {a) }}$ Author to whom correspondence should be addressed. Electronic mail: margrethe.rein@gmail.com.
}

the case of a metal oxide, such depletion might induce a reduction in the oxidation state of the metal. Other chemical changes would be the effect of "knock on" (Ref. 9), which is an incorporation of elements further into the material during sputtering. Another side-effect of ion bombardment is the topological changes at the sample surface, also described in Ref. 9. For both sample cleaning and depth profiling XPS, the possibility of chemical changes must be taken into consideration.

A method which can overcome the influence of contamination and cleaning procedures is in situ XPS. Without breaking vacuum after material deposition, it is possible to carry out XPS studies of ultrathin layers step by step during growth of a thicker film, not influenced by contamination. This paper presents an in situ XPS study of ITO deposited by rf magnetron sputtering onto a monocrystalline silicon substrate at room temperature. It investigates the initial stages of the growth of the ITO film on a Si wafer, which includes the formation of $\mathrm{SiO}_{\mathrm{x}}$ interfacial layer and the presence of metallic indium and tin at the interface.

The ITO was deposited onto a polished p-type Czochralski Si substrate of size $2 \times 2 \mathrm{~cm}$. The orientation of the silicon crystal was $\langle 100\rangle$ and the resistivity $1-3 \Omega \mathrm{cm}$. Prior deposition, the substrate was etched in hydrofluoric acid (HF) $\left(5\right.$ vol. \%) in order to remove any native $\mathrm{SiO}_{\mathrm{x}}$. The substrate was rinsed in deionized (DI) water $(18 \mathrm{M} \Omega \mathrm{cm})$ and blown dry with nitrogen. Subsequent to this treatment, the substrate was mounted to the sample holder and transferred quickly, in nitrogen atmosphere, to the load lock of DAISYMAT (DArmstadt Integrated SYstem for MATerial research). This system is described in Ref. 10. XPS was carried out on the silicon substrate prior to the depositions. As both the deposition chamber and the X-ray spectrometer are connected to DAISY-MAT, the sample was transferred back and forth from deposition to spectroscopy, without breaking the vacuum. The ITO layers were deposited at room 
temperature in four steps of $2,8,30$, and $900 \mathrm{~s}$, giving a total deposition time of $940 \mathrm{~s}$. The substrate to target distance was $10 \mathrm{~cm}$, the working power was $25 \mathrm{~W}$ (power density of $\sim 1.2 \mathrm{~W} / \mathrm{cm}^{2}$ ) and the working pressure was $5 \times 10^{-3}$ mbar. The flow of argon during sputtering was $6 \mathrm{sccm}$ and the target composition was 90 wt. $\% \mathrm{In}_{2} \mathrm{O}_{3}$ and 10 wt. $\% \mathrm{SnO}_{2}$.

XPS was carried out using a Physical Electronics PHI 5700. Monochromatic Al $\mathrm{K} \alpha$ radiation $(h \nu=1486.6 \mathrm{eV})$ was employed as excitation for XPS. XP spectra of In $3 \mathrm{~d}, \mathrm{Sn} 3 \mathrm{~d}$, $\mathrm{O} 1 \mathrm{~s}$, and $\mathrm{Si} 2 \mathrm{p}$ were recorded with a take-off angle of $45^{\circ}$. The XPS results were peak fitted using the fitting program CasaXPS. The background type was Shirley and the fitting components were Guassian/Lorenzian (30\%/70\%) product formulas. Some of the components were also modified by the exponential blend, due to the metallic state of elements.

Cross-sectional transmission electron microscopy (TEM) samples were prepared by ionmilling using a Gatan precision ion polishing system with $5 \mathrm{kV}$ gun voltage. The samples were analyzed by high-resolution TEM (HRTEM) and energy filtered TEM (EFTEM) in a $200 \mathrm{keV}$ JEOL 2010 F microscope with a Gatan imaging filter and detector. The spherical (Cs) and chromatic aberration (Cc) coefficients of the objective lens were 0.5 and $1.1 \mathrm{~mm}$, respectively. The point to point resolution was $0.194 \mathrm{~nm}$ at Scherzer focus $(42 \mathrm{~nm})$.
Secondary ion mass spectroscopy (SIMS) measurements were carried out by the use of a CAMECA ims $7 \mathrm{f}$ instrument. The elements were ionized in negative mode with a $15 \mathrm{keV}$ primary ion beam of $\mathrm{Cs}+$, and the sputtering time was $42480 \mathrm{~s}$. The depth of the sputtered craters was measured with a Dektak 8 surface stylus profilometer.

Figure 1 shows the XPS spectra of In $3 \mathrm{~d}_{5 / 2}, \mathrm{Sn} 3 \mathrm{~d}_{5 / 2}, \mathrm{O}$ $1 \mathrm{~s}$, and $\mathrm{Si} 2 \mathrm{p}$ carried out prior and subsequent to the depositions. The In $3 d_{5 / 2}, S n 3 d_{5 / 2}$, and $\mathrm{O} 1 \mathrm{~s}$ spectra are fitted with two or three components, while the Si 2 p spectra from substrate and after 2, 10, and $40 \mathrm{~s}$ deposition are fitted with two, five, six, and one $\mathrm{Si}_{3 / 2}$ and $\mathrm{Si}_{1 / 2}$ peaks, respectively. No In or Sn peaks are observed prior deposition and no Si peaks after the last deposition. The thicknesses are estimated from TEM images and calculations based on the integrated area of the $\mathrm{Si}$ peaks in the XPS spectra. ${ }^{11}$

The predominant peaks in the In $3 \mathrm{~d}_{5 / 2}$ and $\mathrm{Sn} 3 \mathrm{~d}_{5 / 2}$ spectra after the first deposition for $2 \mathrm{~s}$ are attributed to elemental In and $\mathrm{Sn}$, following a similar analysis procedure as in our previous work. ${ }^{12}$ Pure In is also found after $10 \mathrm{~s}$, while pure $\mathrm{Sn}$ is present both after 10 and $940 \mathrm{~s}$. A segregation of tin to the film surface is previously reported by others. ${ }^{13}$ The mentioned analysis is performed for the predominant $\operatorname{In}_{\mathrm{II}}$ and $\mathrm{Sn}_{\mathrm{II}}$ peaks after 10,40 , and $940 \mathrm{~s}$ as well, and these peaks are assigned to In and $\mathrm{Sn}$ in crystalline ITO.

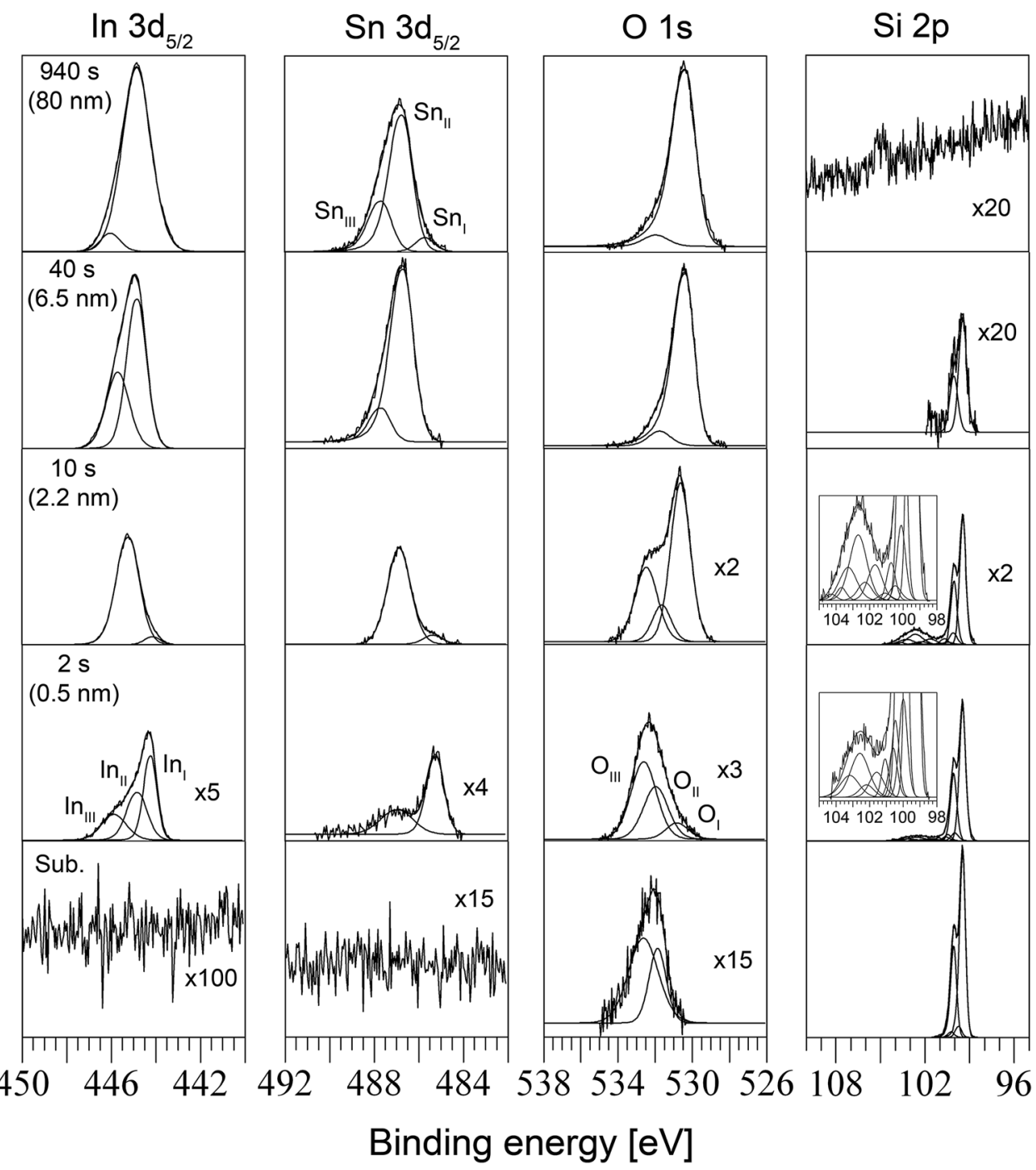

FIG. 1. The XPS spectra and peak fitting of the In $3 d_{5 / 2}$, Sn $3 d_{5 / 2}, O$ s, and Si $2 p$ peaks. The $\mathrm{Si} 2 \mathrm{p}$ spectra include $\mathrm{SiO}_{x}$ insets. The intensities of some spectra are enhanced with the indicated factors. 


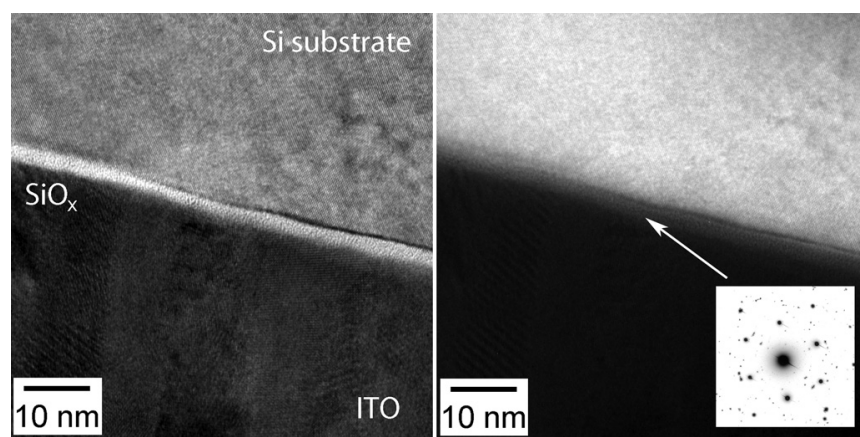

FIG. 2. Energy filtered TEM images using the plasmon peak of (a) $\mathrm{SiO}_{2}$ at $23 \mathrm{eV}$, and (b) for $\mathrm{Si}$ at $16 \mathrm{eV}$.

In the previous work, we argued that In components at $444.9 \mathrm{eV}$ and $446.0 \mathrm{eV}$ (energy separation of $1.1 \mathrm{eV}$ ) could be attributed to crystalline and amorphous ITO, respectively. ${ }^{12}$ By further examination, applying the electroneutrality principle, the presence of amorphous ITO has been excluded. ${ }^{13}$ We can confirm this conclusion by analysis of TEM images (Fig. 2) showing no diffuse circles in the diffraction pattern.

The origin of the minor peaks $\operatorname{In}_{\text {III }}$ (at 445.9, 445.7, and $446.0 \mathrm{eV}$ after 2, 40, and $940 \mathrm{~s}$, respectively) and $\mathrm{Sn}_{\text {III }}(487.7$ and $487.5 \mathrm{eV}$ after 40 and $940 \mathrm{~s}$, respectively) could be related to hydrogen, as hydrogen was detected by SIMS in both bulk and interfacial ITO (Fig. 3). The position of the $\mathrm{In}_{\text {III }}$ component coincides with the $\mathrm{In}(\mathrm{OH})_{3}$ state $(445.8 \mathrm{eV})$ in Ref. 14. Similarly, the high binding energy peak $\mathrm{Sn}_{\text {III }}$ could be assigned to bonds between hydrogen and $\mathrm{Sn}$. Another explanation could be plasmon excitation. This is previously discussed by Christou et al. ${ }^{15}$ and Gassenbauer et al. ${ }^{16}$

The two O 1s components found at the Si wafer surface $(531.9$ and $532.6 \mathrm{eV})$ are most likely due to water molecules and contamination adsorbed at the substrate surface, originated from the DI water rinsing or exposure to air. The values coincide with the binding energies for hydroxides, contamination, and oxygen due to air exposure $(531.7 \pm 0.2$ and $532.7 \pm 0.2 \mathrm{eV}$ ) reported by Plá et al. ${ }^{17}$ Hydroxides are plausible as the substrate was cleaned in HF and rinsed in DI water. $\mathrm{OH}$ groups at $\mathrm{Si}(100)$ wafers after $\mathrm{HF}$ etch and $\mathrm{DI}$ water rinsing are previously detected using high resolution electron energy loss spectroscopy (HREELS). ${ }^{18}$ Contamination due to air exposure is also plausible as traces of carbon were detected at the substrate surface and after $2 \mathrm{~s}$ deposition (not illustrated).

After $2 \mathrm{~s}$ of deposition, the predominant $\mathrm{O} 1 \mathrm{~s}$ peak is at $532.6 \mathrm{eV}\left(\mathrm{O}_{\mathrm{III}}\right)$. The intensity of this peak increases slightly after the next deposition (not illustrated in the figure) and disappears after further deposition. Hence, this binding energy is more likely due to other chemical states than found at the substrate surface. An obvious explanation of the origin would be compounds of oxygen and silicon as $\mathrm{SiO}_{\mathrm{x}}$ is observed as a shoulder after 2 and $10 \mathrm{~s}$ in the Si $2 \mathrm{p}$ spectra (discussed below). A binding energy of $532.6 \mathrm{eV}$ is reported by Wagner et al. of thermally oxidized silicon wafer. ${ }^{19}$ The interfacial $\mathrm{SiO}_{\mathrm{x}}$ layer is also observed by TEM and SIMS in Figs. 2 and 3, respectively.

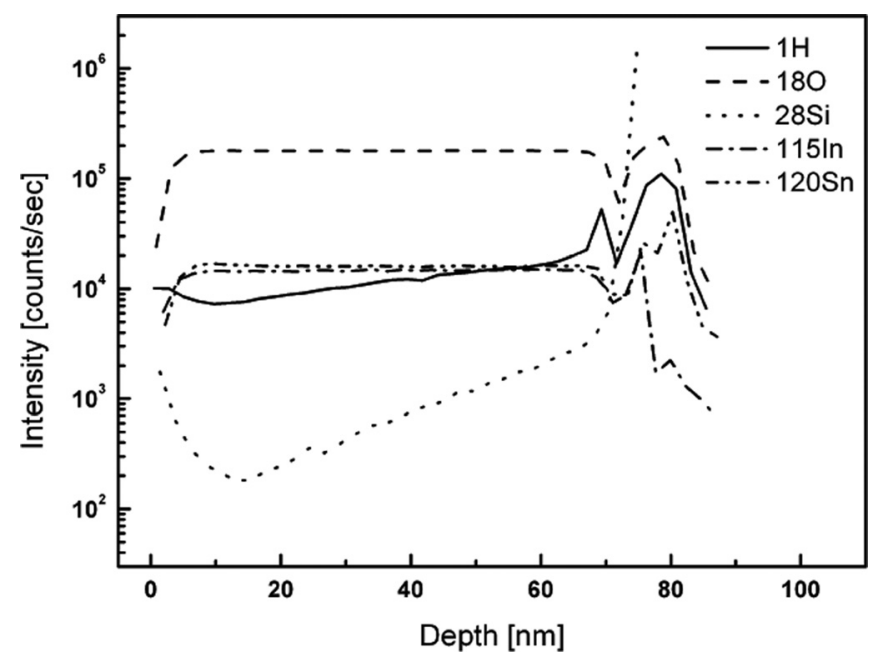

FIG. 3. SIMS of the ITO/Si interface and $\mathrm{SiO}_{\mathrm{x}}$ interfacial layer.

The analysis of the $\mathrm{O}_{\mathrm{I}}$ and $\mathrm{O}_{\text {II }}$ components found after deposition is similar to our previous work. ${ }^{12}$ Both peaks are attributed to crystalline ITO, the $\mathrm{O}_{\text {II }}$ component related to $\mathrm{O}^{2-}$ ions at oxygen deficient sites.

The binding energy, full width at half maximum (FWHM), and chemical shift of the $\mathrm{Si} 2 \mathrm{p}$ and $\mathrm{SiO}_{x}$ peaks were fitted as shown in our previous work. ${ }^{20}$ In addition to the Si $2 p$ peaks corresponding to the $2 p_{1 / 2}$ and $2 p_{3 / 2}$ spin states, two small components with binding energy in the range $99.8-100.6 \mathrm{eV}$ are found. These small components are attributed to silicon bonded to hydrogen, according to Thøgersen $e t a l .{ }^{20}$ In that work, a peak with binding energy at $99.7 \mathrm{eV}$ was attributed to $\mathrm{Si}_{3} \mathrm{SiH}$ and is close to our value $(99.8 \mathrm{eV})$. The two small components at 100.1 and $100.6 \mathrm{eV}$ after $10 \mathrm{~s}$ can be attributed to $\mathrm{Si}_{2} \mathrm{SiH}_{2}$, which has a binding energy $0.57 \mathrm{eV}$ higher than elemental $\mathrm{Si}^{21}$

The $\mathrm{SiO}_{\mathrm{x}}$ shoulder with a peak position at $102.6 \mathrm{eV}$ is fitted by three and four components after 2 and $10 \mathrm{~s}$ deposition, respectively. The components in the decomposed $\mathrm{SiO}_{\mathrm{x}}$ peak correspond to the $\mathrm{Si}_{2} \mathrm{O}, \mathrm{SiO}, \mathrm{Si}_{2} \mathrm{O}_{3}$ (suboxides) and

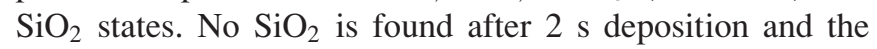
predominant peaks correspond to the $\mathrm{Si}_{2} \mathrm{O}$ and $\mathrm{Si}_{2} \mathrm{O}_{3}$ suboxide states. After $10 \mathrm{~s}$ deposition, the $\mathrm{Si}_{2} \mathrm{O}_{3}$ peaks are predominant and small peaks corresponding to the $\mathrm{SiO}_{2}$ state are present. These results show that $\mathrm{SiO}_{2}$ is not the dominating oxide in the $\mathrm{SiO}_{\mathrm{x}}$ interfacial layer between ITO and $\mathrm{Si}$.

From the literature, it is known that oxidation of suboxides requires heat at a certain level. He et al. found that suboxides oxidize into $\mathrm{SiO}_{2}$ when annealing at high temperatures $(>1000 \mathrm{~K}){ }^{22}$ Zhang et al. reported changes in concentration of the different suboxides due to increased annealing temperature, though low annealing temperature $\left(<400^{\circ} \mathrm{C}\right)$ did not change the concentration of $\mathrm{Si}_{2} \mathrm{O}$ and $\mathrm{Si}_{2} \mathrm{O}_{3}$ states. ${ }^{23}$ According to this information, we assume that the presence of $\mathrm{SiO}_{2}$ in the $\mathrm{SiO}_{\mathrm{x}}$ layer is significantly low throughout the layer as our sample did not undergo heat treatment.

The presence of suboxides may introduce another band gap than $\mathrm{SiO}_{2}$ in the $\mathrm{SiO}_{\mathrm{x}}$ layer. A narrower band gap for suboxides in a $\mathrm{SiO}_{2} / \mathrm{n}$-type $\mathrm{Si}(111)$ interface region is calculated by Yamashita et al. ${ }^{24}$ They have shown that the main oxides in a thin interface region between a $\mathrm{Si}$ substrate and a $\mathrm{SiO}_{2}$ film are $\mathrm{Si}_{2} \mathrm{O}$ and $\mathrm{Si}_{2} \mathrm{O}_{3}$ and that the band gap increases 
as the oxidation state increases $\left(E_{g}\left(\mathrm{Si}_{2} \mathrm{O}\right)<E_{g}\left(\mathrm{Si}_{2} \mathrm{O}_{3}\right)\right.$ $\left.<E_{g}\left(\mathrm{SiO}_{2}\right)\right)$. A different band gap alignment of the ITO/Si interface than in the case of $\mathrm{SiO}_{2}$ as the main silicon oxide and the presence of metallic In and Sn at the interface may play a significant role in the carrier transport mechanism in the ITO/Si junction. The prominent presence of suboxides at the ITO/Si interface and the likely effect on the tunneling probability through the $\mathrm{SiO}_{\mathrm{x}}$ layer has previously been put forward by Kobayashi et al. ${ }^{25}$

In conclusion, this in situ XPS study qualitatively confirms previous ex situ XPS results. We have shown that both elemental In and Sn are present at the ITO/Si interface. Our study also reveals that suboxides are predominant in the interfacial $\mathrm{SiO}_{\mathrm{x}}$ layer. This may have an impact on the carrier transport properties at the ITO/Si interface.

The authors would like to thank Lasse Vines for performing the SIMS characterization. The work was funded by REC Solar, the Research Council in Norway, through the Nanomat program, and the XPS work in Darmstadt has been supported by the Deutsche Forschungsgemeinschaft (DFG) within the collaborative research center SFB 595.

${ }^{1}$ S. Ray, R. Banerjee, N. Basu, A. Batabyal, and A. Barua, J. Appl. Phys. 54, 3497 (1983).

${ }^{2}$ C. Ow-Yang, Y. Shigesato, and D. Paine, J. Appl. Phys. 88, 3717 (2000).

${ }^{3}$ J. Shewchun, J. Dubow, C. Wilmsen, R. Singh, D. Burk, and J. Wager, J. Appl. Phys. 50, 2832 (1979).

${ }^{4}$ S. Goodnick, J. Wager, and C. Wilmsen, J. Appl. Phys. 51, 527 (1980).

${ }^{5}$ S. Diplas, O. M. Lovvik, H. Nordmark, D. M. Kepaptsoglou, J. M. Graff, C. Ladam, F. Tyholdt, J. C. Walmsley, A. E. Gunnaes, R. Fagerberg, and A. Ulyashin, Surf. Interface Anal. 42, 874 (2010).

${ }^{6}$ A. Montesdeoca-Santana, E. Jimenez-Rodriguez, N. Marrero, B. Gonzalez-Diaz, D. Borchert, and R. Guerrero-Lemus, Nucl. Instrum. Methods Phys. Res. B 268, 374 (2010).
${ }^{7}$ S. Sheng, H. Hao, H. Diao, X. Zeng, Y. Xu, X. Liao, and T. L. Monchesky, Appl. Surf. Sci. 253, 1677 (2006).

${ }^{8}$ K. Sugiyama, H. Ishii, Y. Ouchi, and K. Seki, J. Appl. Phys. 87, 295 (2000).

${ }^{9}$ J. C. Riviere, Practical Surface Analysis by Auger and X-ray Photoelectron Spectroscopy, edited by D. Briggs and M. P. Seah (Wiley, Chichester, 1983), pp. 17-85.

${ }^{10}$ D. Ensling, A. Thissen, Y. Gassenbauer, A. Klein, and W. Jaegermann, Adv. Eng. Mater. 7, 945 (2005).

${ }^{11}$ M. P. Seah, Practical Surface Analysis by Auger and X-ray Photoelectron Spectroscopy, edited by D. Briggs and M. P. Seah (Wiley, Chichester, 1983), pp. 181-216.

${ }^{12}$ A. Thøgersen, M. Rein, E. Monakhov, J. Mayandi, and S. Diplas, J. Appl. Phys. 109, 113532 (2011).

${ }^{13}$ J. Kim, P. Ho, D. Thomas, R. Friend, F. Cacialli, G. Bao, and S. Li, Chem. Phys. Lett. 315, 307 (1999).

${ }^{14}$ C. D. Wagner, Practical Surface Analysis by Auger and X-ray Photoelectron Spectroscopy, edited by D. Briggs and M. P. Seah (Wiley, Chichester, 1983), pp. 477-509.

${ }^{15}$ V. Christou, M. Etchells, O. Renault, P. J. Dobson, O. V. Salata, G. Beamson, and R. G. Egdell, J. Appl. Phys. 88, 5180 (2000).

${ }^{16}$ Y. Gassenbauer, R. Schafranek, A. Klein, S. Zafeiratos, M. Havecker, A. Knop-Gericke, and R. Schlogl, Phys. Rev. B 73, 245312 (2006).

${ }^{17}$ J. Pla, M. Tamasi, R. Rizzoli, M. Losurdo, E. Centurioni, C. Summonte, and F. Rubinelli, Thin Solid Films 425, 185 (2003).

${ }^{18}$ D. Graf, M. Grundner, R. Schulz, and L. Muhlhoff, J. Appl. Phys. 68, 5155 (1990).

${ }^{19}$ C. Wagner, D. Passoja, H. Hillery, T. Kinisky, H. Six, W. Jansen, and J. Taylor, J. Vac. Sci. Technol. 21, 933 (1982).

${ }^{20}$ A. Thøgersen, J. H. Selj, and E. S. Marstein, J. Electrochem. Soc. 159, D276 (2012).

${ }^{21}$ G. Cerofolini, C. Galati, and L. Renna, Surf. Interface Anal. 35, 968 (2003).

${ }^{22}$ J. He, X. Xu, J. Corneille, and D. Goodman, Surf. Sci. 279, 119 (1992).

${ }^{23}$ W. Zhang, S. Zhang, Y. Liu, and T. Chen, J. Cryst. Growth 311, 1296 (2009).

${ }^{24}$ Y. Yamashita, S. Yamamoto, K. Mukai, J. Yoshinobu, Y. Harada, T. Tokushima, T. Takeuchi, Y. Takata, S. Shin, K. Akagi, and S. Tsuneyuki, Phys. Rev. B 73, 045336 (2006).

${ }^{25}$ H. Kobayashi, T. Ishida, Y. Nakato, and H. Tsubomura, J. Appl. Phys. 69, 1736 (1991).

This article may be downloaded for personal use only. Any other use requires prior permission of the author and AIP Publishing. This article appeared in (Appl. Phys. Lett. 102, 021606 (2013)) and may be found at (https://doi.org/10.1063/1.4774404).

Available under only the rights of use according to UrhG. 